\title{
Simulation of the Ozone Monitoring Instrument Aerosol Index using the NASA Goddard Earth Observing System Aerosol Reanalysis Products
}

Peter R. Colarco ${ }^{1}$, Santiago Gassó ${ }^{2,3}$, Changwoo Ahn ${ }^{1,4}$, Virginie Buchard ${ }^{5,6}$, Arlindo M. da Silva, 5 Omar Torres $^{1}$

${ }^{1}$ Atmospheric Chemistry and Dynamics Laboratory, NASA Goddard Space Flight Center, Greenbelt, MD, 20770, USA

${ }^{2}$ Climate and Radiation Laboratory, NASA Goddard Space Flight Center, Greenbelt, MD, 20770, USA

${ }^{3}$ GESTAR/Morgan State University, Baltimore, MD, 21251, USA

${ }^{4}$ Science Systems and Applications Inc., Lanham, MD, 20706, USA

$10{ }^{5}$ Global Modeling and Assimilation Office, NASA Goddard Space Flight Center, Greenbelt, MD, 20770, USA

${ }^{6}$ GESTAR/Universities Space Research Association, Columbia, MD, 21046, USA

Correspondence to: Peter R. Colarco (Peter.R.Colarco@nasa.gov)

Supplementary figures 

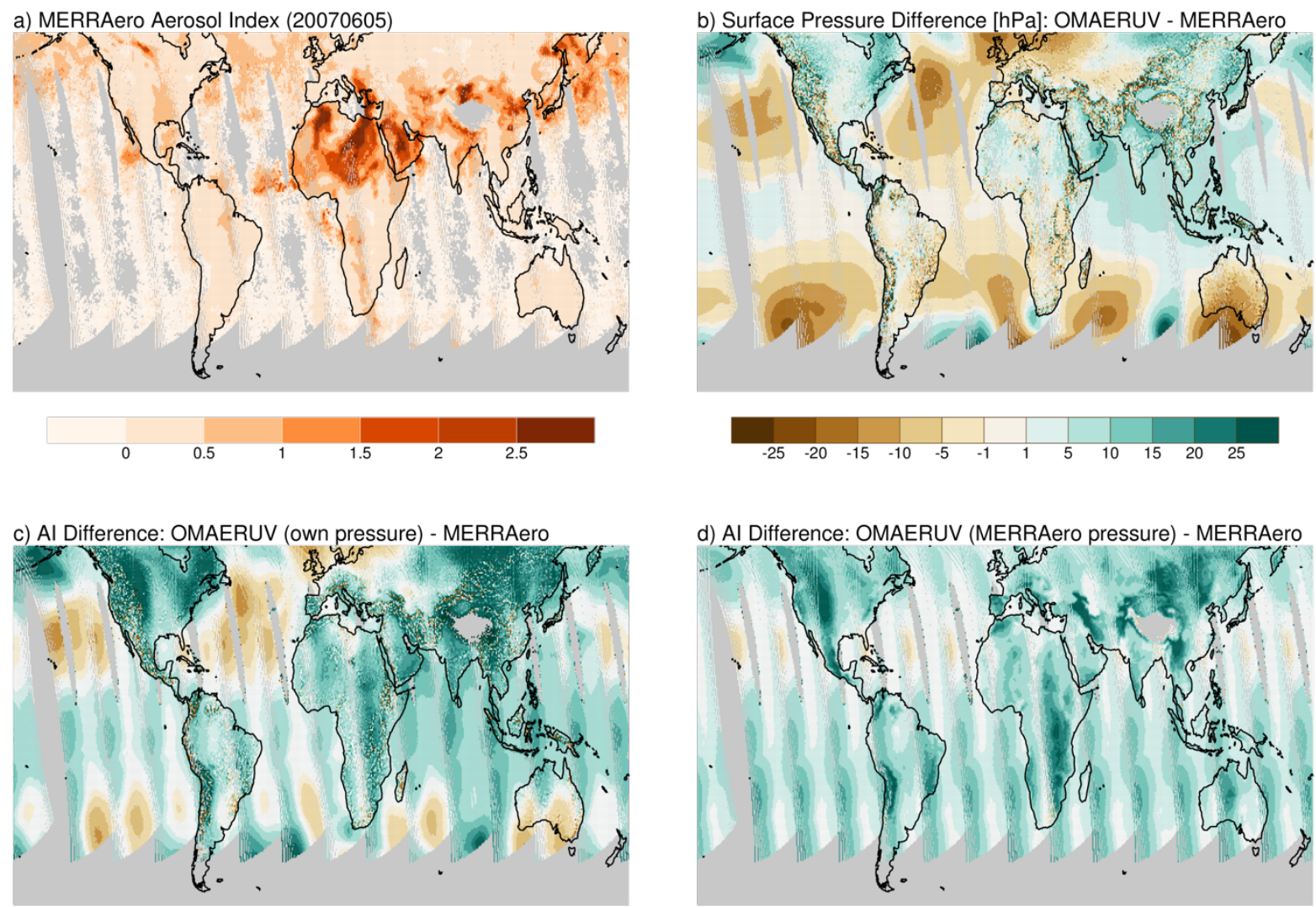

$\begin{array}{lllllllllllll}-0.25 & -0.2 & -0.15 & -0.1 & -0.05 & -0.025 & 0.025 & 0.05 & 0.1 & 0.15 & 0.2 & 0.25 & 0.5\end{array}$

Figure S1: As in Figure 1, for June 5, 2007, but including all surface pressures. 


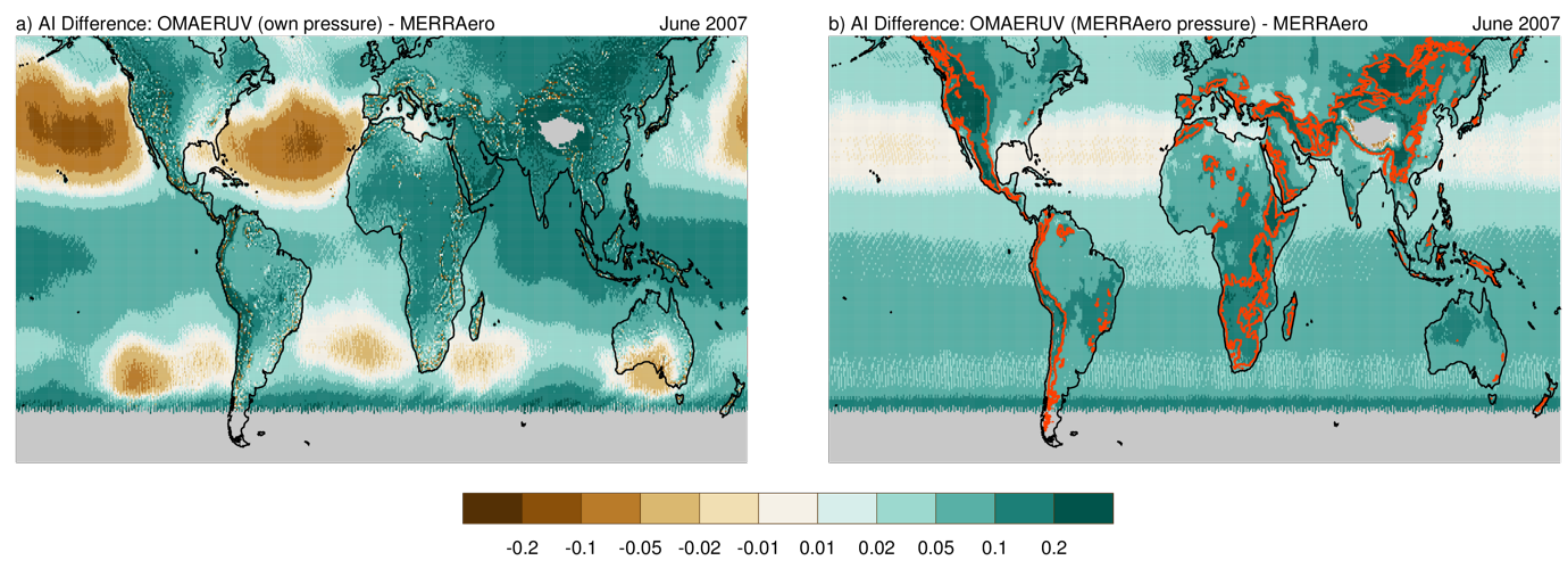

Figure S2: As in Figure 3 for June 2007, but including all surface pressures. 
a) AI Difference: OMAERUV (MERRAero pressure) - MERRAero

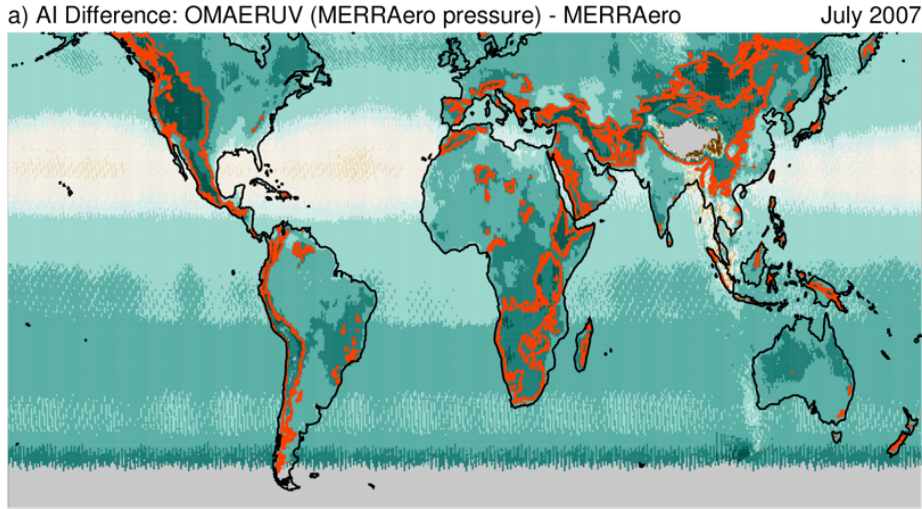

b) AI Difference: OMAERUV (MERRAero pressure) - MERRAero August 2007

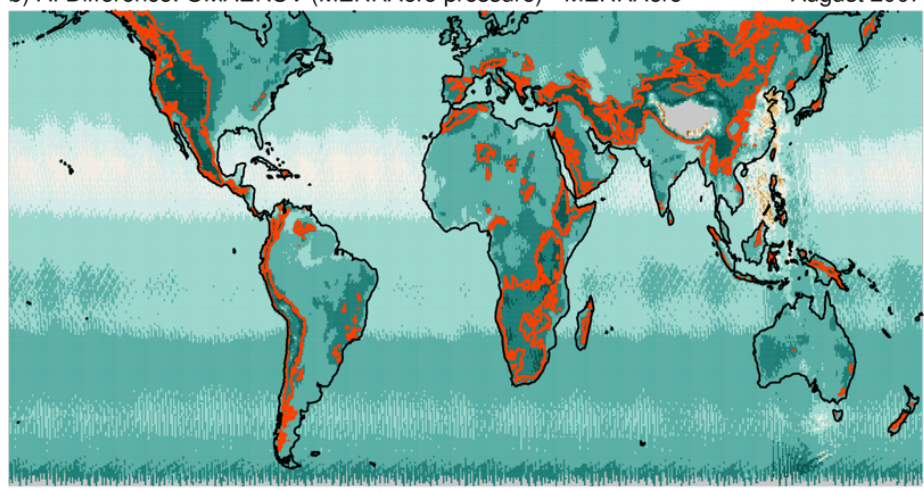

c) AI Difference: OMAERUV (MERRAero pressure) - MERRAero September 2007
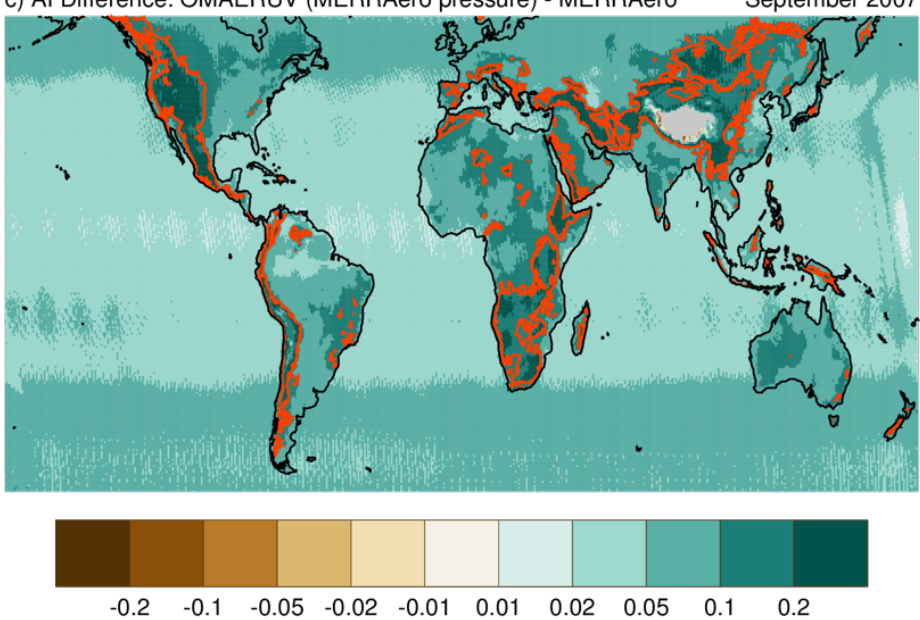

Figure S3: As in Figure 4, but including all surface pressures. 